\title{
Estudo de caso e sala cooperativa Jigsaw na promoção da aprendizagem de periculosidade de substâncias químicas
}

\section{Case Study and Jigsaw Classroom in promoting of learning about risk for chemical substances}

\author{
${ }^{1}$ Manoela Barros Guimarães manoela_bg@hotmail.com \\ 2 Denise Leal de Castro denise.castro@ifrj.edu.br
}

\section{RESUMO}

A pesquisa aborda a aplicação da metodologia de Estudo de Caso, em uma turma do curso técnico em segurança do trabalho, na disciplina Química. O caso incentiva a tomada de decisão dos alunos ao confeccionarem uma cartilha lúdica sobre a periculosidade das substâncias químicas, a fim de conscientizar trabalhadores de uma refinaria de petróleo sobre os riscos químicos. Para o estudo de produtos perigosos, foi adotada a sala de aprendizagem cooperativa Jigsaw durante quatro encontros e os alunos construíram mapas conceituais sobre às classes. A associação das metodologias ativas de ensino proporcionou um ambiente interativo e motivador para os alunos.

Palavras-chave: Sala cooperativa Jigsaw. Estudo de caso. Segurança no trabalho.

\begin{abstract}
This study approaches the application of the case study method, in a group of middle school students from a technical course on occupational safety, in the discipline of Chemistry. The case stimulates decision forcing of the students when confectioning an educational leaflet about risk for chemical substances, to make employee aware of an oil refinery on the chemical risks. For the study of dangerous products, the Jigsaw classroom, teaching cooperative technique, was adopted during four meeting and the students had constructed concept maps about the dangerous substance class. The association of the active teaching methodologies provided an ambient interactive and motivator for the students.
\end{abstract}

Keywords: Jigsaw Classroom. Case Study. Occupational Safety.

\footnotetext{
1 Mestranda em Ensino de Ciências (IFRJ). Licenciada em Química (IFF). Instituto Federal do Rio de Janeiro, Campus Nilópolis.

2 Doutora em Ciências. Docente do programa de pós-graduação stricto sensu em ensino de Ciências. Instituto Federal do Rio de Janeiro, Campus Nilópolis.
} 


\section{INTRODUÇÃO}

Metodologias ativas de ensino tem se tornado essencial na transformação do âmbito escolar, uma vez que possibilita o aluno atuar como protagonista da aprendizagem, ou seja, exercer o papel de agente ativo na sala de aula (ARAÚJO, et. al., 2014). Nesse modelo de ensino, o discente, de modo autônomo, estabelece um contato com o conteúdo em estudo não de modo passivo, mas sim ativamente, isto é, o aluno é posto em uma condição proativa. A construção do conhecimento ocorre a partir da vivência do educando com contextos reais ou simulados que auxiliam no desenvolvimento de um pensamento crítico e reflexivo por parte do aluno (BERBEL, 2011). Como o uso de metodologias ativas permitem que o estudante desempenhe uma autonomia e o protagonismo, é necessário haver organização e disciplina para desfrutar desses benefícios adicionais.

O papel do professor, nessa abordagem, é atuar como um intermediador e facilitador, aconselhando os alunos a administrarem o tempo de estudo de modo eficaz e orientando os a escolherem as fontes de informação de maneira eficiente, além de contribuir na promoção de autonomia por parte dos alunos (BERBEL, 2011).

São inúmeras as vertentes de metodologias ativas que assumem um potencial de estimular os discentes a desenvolverem: a motivação própria; o engajamento e persistência; a exteriorização de criatividade; e melhorias nos resultados escolares. Entretanto, é válido ressaltar que a metodologia ativa por si só não exerce a capacidade de transformar uma realidade, é preciso que os envolvidos no processo compreendam a metodologia e tenham expectativas em seu potencial pedagógico (BERBEL, 2011). O presente trabalho tem por objetivo principal associar metodologias ativas de ensino, na pretensão de estimular os alunos a assumirem uma postura ativa, além de se sentirem motivados a aprender o tema em questão de modo cooperativo. As metodologias de ensino são: Estudos de Caso e Aprendizagem Cooperativa Jigsaw.

\section{REVISÃO DA LITERATURA}

O método de Estudos de Caso é uma variante do método Aprendizagem Baseada em Problemas, oriunda do método Problem Based Learning (PBL). Consiste no uso de narrativas sobre dilemas vividos por indivíduos que precisam tomar decisões para os problemas enfrentados (SÁ; QUEIROZ, 2009).

Para construir um estudo de caso faz-se necessário conhecer quatro trajetos aconselhados por Sá e Quei$\operatorname{roz}(2009$, p.25).

1. Selecionar o assunto central a ser abordado no caso, de modo que seja aplicado no contexto vivenciado pelo aluno, se encaixe com o tema discutido em sala e relacione com os temas atuais.

2. Listar os conceitos que se pretende estudar a partir da aplicação do caso, a fim de que sejam inseridas questões que direcionem trabalhar tais conceitos.

3. Criar os personagens visando produzir uma empatia com os estudantes, por isso eles devem possuir características que gerem uma motivação nos alunos.

4. Elaborar as questões que serão discutidas em sala, considerando os objetivos pretendidos, os conceitos estudados e as atitudes que devem ser assumidas para solucionar o caso.

Após seguir esses conselhos, a narrativa poderá ser confeccionada. Para esse momento prático, Herreid (1994) lista uma sequência de ações que facilitam construir um bom caso investigativo. O caso investigativo deve narrar uma história contendo diálogos entre os personagens principais, a qual deve produzir uma empatia com o leitor. Para isso, o caso deve apresentar um enredo que seja relevante e conectado com a realidade do 
estudante, para despertá-lo a ter interesse pela questão. O caso deve tratar de um assunto atual e ser curto, para impedir que a leitura seja tediosa para o aluno. É importante que o caso tenha uma utilidade pedagógica, possua generalizações e provoque um conflito que force a tomada de decisão para solucioná-lo (SÁ; QUEIROZ, 2009).

A sala cooperativa Jigsaw é uma estratégia que foi desenvolvida por Elliot Aronson, com o intuito de transformar a atmosfera competitiva entre os alunos em um ambiente cooperativo (MENGDUO; XIAOLING, 2010). A solução identificada foi estruturar os alunos em grupos para realizarem as atividades de modo colaborativo. A Figura 1 representa um esquema detalhado da atividade baseada nesse método cooperativo de aprendizagem.

Figura 1 Representação esquemática de atividade baseada no método cooperativo de aprendizagem Jigsaw.

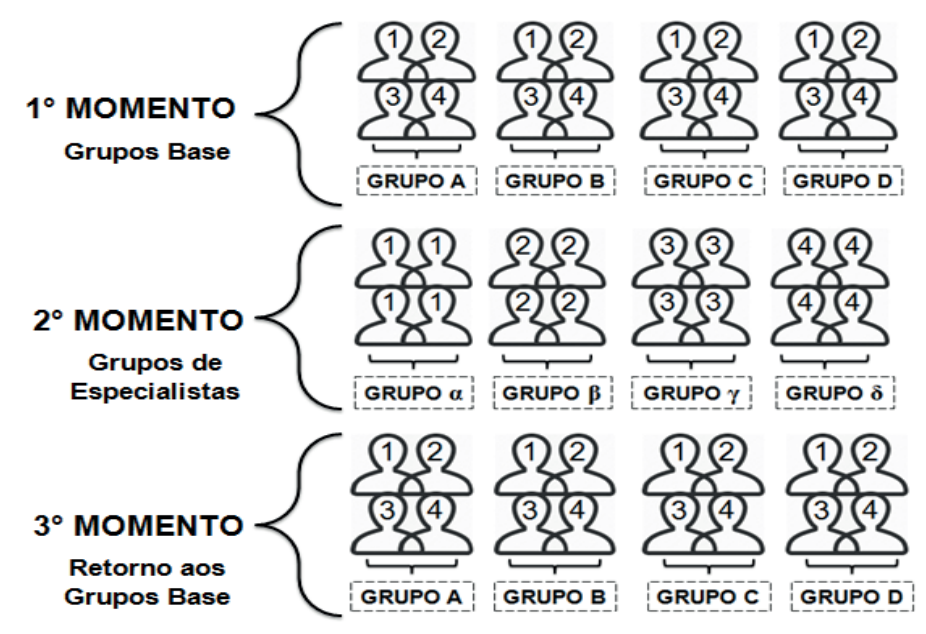

Fonte: Adaptado de FATARELI, FERREIRA, FERREIRA; QUEIROZ, 2010, p. 162.

No referido método, no primeiro momento os discentes são distribuídos em grupos heterogêneos denominados grupos de base e os conteúdos a serem estudados são divididos entre os grupos formados (Grupo A, Grupo B, Grupo C e Grupo D). Um determinado tópico é discutido por todos os integrantes (1, 2, 3 e 4) de cada grupo. O tópico é subdivido em subtópicos do mesmo número dos membros do grupo. No segundo momento, cada aluno discute e estuda com os integrantes de outros grupos que possuem o mesmo subtópico, formando o grupo dos especialistas (Grupo $\alpha$, Grupo $\beta$, Grupo y e Grupo $\delta$ ). No terceiro momento, os discentes retornam aos grupos de base e expõem o que aprenderam aos seus colegas, de modo que todo conhecimento seja reunido e haja uma compreensão do tópico em questão de modo integral. Durante o processo, cada aluno deve aprender o conteúdo estudado para si e ser capaz de explicar claramente aos seus colegas o que foi aprendido. Sendo assim, todos os integrantes são avaliados ao relatarem de modo individual a respeito dos conteúdos estudados (COCHITO, 2004).

\section{PERCURSO METODOLÓGICO}

A proposta da pesquisa consistiu na implementação de um estudo de caso na disciplina de química em uma turma subsequente do curso técnico em segurança de trabalho de uma Instituição Federal do Norte do estado do Rio de Janeiro, localizado no Brasil. O público alvo do trabalho, foram 24 alunos.

Após ter definido o público-alvo, seguiram-se as orientações de Sá e Queiroz (2009) descritos na introdução, para a construção do caso investigativo. Como os alunos estão estudando para se formarem técnicos em segurança do trabalho, buscou-se selecionar um assunto que envolva um contexto possível de ser vivenciado por eles ao atuarem na área. Também foram listados os conteúdos que se pretendia estudar a partir da aplicação do caso, baseando-se na ementa do curso disponibilizada pela Instituição. Refletiu-se sobre os protagonistas que seriam mencionados no caso, com intuito de criar personagens que produzisse uma empatia com os estudantes. Por fim, consideraram-se os objetivos pretendidos com a solução do caso. 
Finalmente, os passos orientados por Herreid (1994) foram seguidos para a construção de um bom caso investigativo. A Figura 2 apresenta o caso investigativo construído no formato de história em quadrinho (HQ) e a Figura 3, a seguir, expõe uma orientação aos alunos a respeito do planejamento para a confecção da cartilha lúdica solicitada como resolução do caso.

Figura 2. Caso investigativo "Melhor prevenir do que remediar".

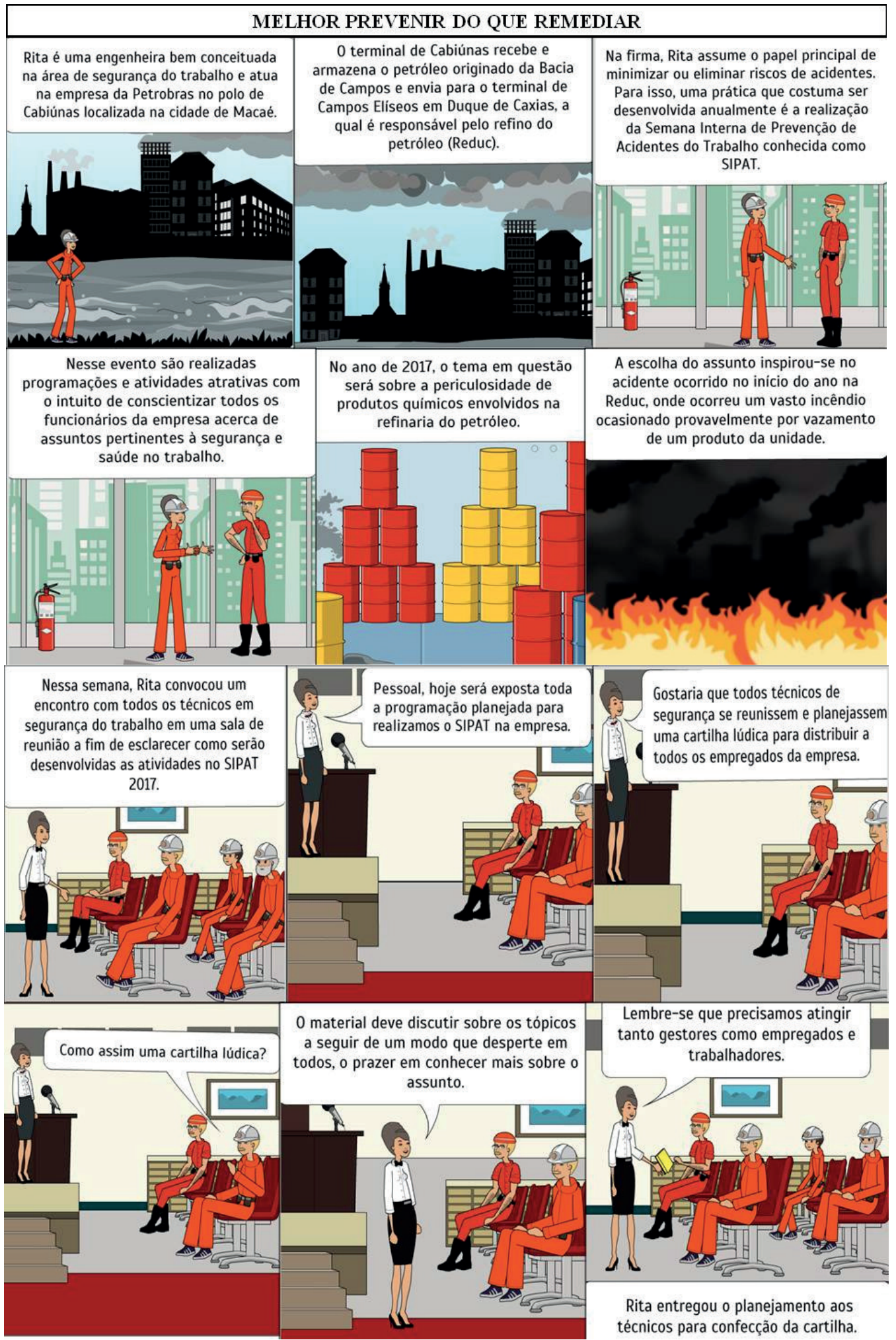

Fonte: Arquivo próprio. 
Figura 3. Orientação sobre o planejamento para a criação da cartilha lúdica.

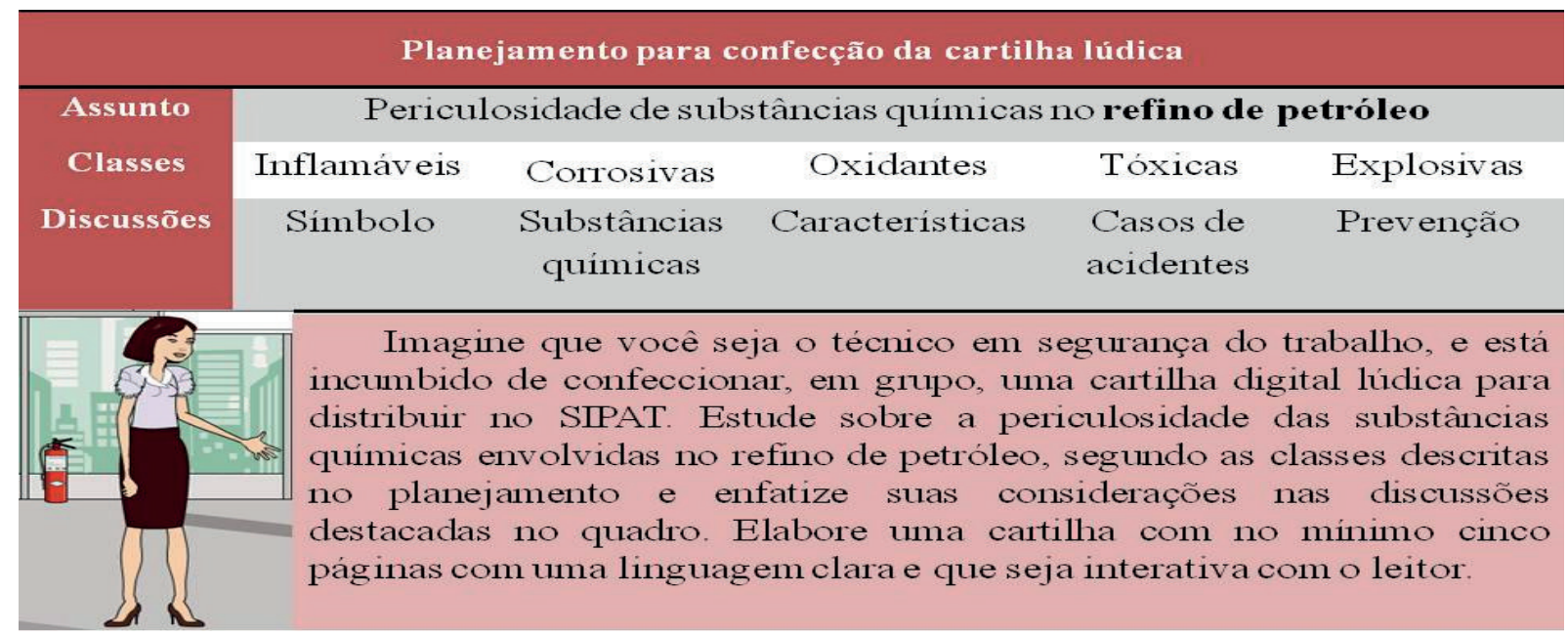

Fonte: Arquivo próprio.

O caso narra a atuação de uma engenheira da área de segurança do trabalho, na empresa da Petrobrás, que organiza a Semana Interna de Prevenção de Acidentes do Trabalho de 2017 (SIPAT), voltada para discussões sobre a periculosidade de produtos químicos. Esse assunto a ser tratado surge devido a um incêndio ocorrido, de fato, em uma unidade de refino de petróleo em Duque de Caxias, no estado do Rio de Janeiro, por vazamento de um produto da unidade.

No caso, a engenheira convoca um encontro com os técnicos em segurança do trabalho e solicita que todos planejem, em grupos, uma cartilha lúdica digital para distribuir a todos os empregados da empresa para conscientizá-los. A cartilha deve abordar discussões sobre o símbolo, substâncias químicas, características, casos de acidentes e prevenção das seguintes classes de produtos perigosos: inflamáveis, corrosivas, oxidantes, tóxicas e explosivas. Ao final, os alunos são estimulados a estudarem sobre a periculosidade das substâncias químicas envolvidas no refino de petróleo, e a assumir a postura do técnico em segurança do trabalho para a elaboração de uma cartilha lúdica que seja interativa com o leitor.

Para o estudo das classes de produtos perigosos, a sala de aprendizagem cooperativa Jigsaw foi adotada durante quatro encontros realizados com a turma. Esse método cooperativo de aprendizagem é altamente estruturado e sua dinâmica exige uma interdependência entre os alunos, a qual todos participam ativamente no desenvolvimento da proposta. No primeiro encontro, após a leitura do caso, os alunos se reuniram em cinco grupos de base para leitura individual de um material sobre a periculosidade das substâncias químicas. No segundo encontro, os alunos sorteados, para compor os grupos especialistas, discutiram sobre tópicos específicos. Formaram-se cinco grupos especialistas referentes às cinco classes de substâncias perigosas destacadas no final do caso. Cada grupo especialista assumiu o compromisso de compreender detalhadamente um subtópico das classes de produtos perigosos e construíram um mapa conceitual. No terceiro encontro, os alunos retornaram aos respectivos grupos de base e uma troca de significados ocorreu, quando cada integrante do grupo de base compartilhou o mapa conceitual. Ainda no terceiro encontro, os grupos de base compartilharam ideias sobre a elaboração e apresentação da cartilha lúdica. No quarto encontro, todos os cinco grupos de base apresentaram suas cartilhas para solução do caso.

\section{RESULTADOS E DISCUSSÕES}

No primeiro encontro dos grupos de base, os alunos tiveram uma visão inicial e geral com relação ao assunto a ser aprendido, a partir da leitura de um artigo que relatava as condições de trabalho nas plataformas de 
petróleo. O texto exemplificava os casos de acidentes e incêndios ocasionados por substâncias perigosas, como vazamentos de gases inflamáveis ou substâncias altamente tóxicas. Com a leitura do texto, os alunos puderam relembrar alguns casos de plataformas que foram vítimas de acidentes. Nesse momento, identificou-se um interesse dos alunos, uma vez que questionaram suas dúvidas e estavam utilizando marcadores de textos para destacar, o que na sua visão, era essencial para futuras discussões do seu assunto.

Na reunião dos grupos especialistas, os alunos deveriam diferenciar com mais detalhe e especificidade os tópicos especialistas. Durante a construção dos mapas conceituais, observou-se uma motivação dos grupos, e uma negociação de conceitos ocorreu entre os integrantes. As informações eram compartilhadas, os alunos apresentavam suas considerações, discutiam acerca das palavras chaves, ideias para compor o mapa conceitual, e sanaram suas dúvidas com os professores ao longo do processo. A pesquisadora se posicionou como mediadora durante a realização da atividade e estava disposta a esclarecer todas as dúvidas apresentadas pelos alunos.

Para a construção dos mapas conceituais, aconselhou-se aos integrantes retomarem aos aspectos mais gerais, intermediários e específicos do seu tópico especialista. Um dos mapas que atendeu esse requisito será brevemente explicitado. Destaca-se como exemplo o mapa confeccionado pelo grupo especialista da classe das substâncias inflamáveis. A Figura 4a e a Figura 4b representam o mapa conceitual do tópico inflamável. Vale-se ressaltar que o grupo especialista da classe das substâncias inflamáveis estruturou um único mapa mental detalhando os líquidos inflamáveis e os sólidos inflamáveis. Entretanto, para melhor visualização e compreensão dos conceitos abordados pelo grupo, no presente trabalho, priorizou-se organizá-los em duas figuras (Figura 4a e 4b).

Uma breve análise desses mapas será explicitado respaldando-se nos três critérios estipulados por Moreno et al (2007) que compreende:

1. Conceitos: quantidade e qualidade de conceitos apresentados e níveis de hierarquia conceitual, buscando identificar conceitos mais amplos até os mais específicos, incluindo exemplos, obtendo-se uma média aritmética dos parâmetros analisados.

2. Inter-relações entre conceitos: linhas de entrecruzamento, número de palavras de enlace e proposições com significado lógico, do ponto de vista semântico. Neste critério, procedeu-se a uma quantificação das linhas de entrecruzamento e palavras de enlace, bem como a uma qualificação das proposições com base no significado lógico.

3. Estrutura do mapa: sequencial ou em rede, presença de relações cruzadas (inter-relações não hierárquicas entre segmentos distantes do mapa, as quais estabelecem novas relações entre conceitos ou campos de conceitos), representatividade do conteúdo em relação aos conteúdos abordados nas disciplinas, e criatividade, relacionada à estética do diagrama. Esses critérios, fundamentalmente de enfoque qualitativo, buscam uma leitura que amplie e integre os dados obtidos nos critérios anteriores, e parte da análise do formato escolhido pelos mestrandos para traduzirem suas aprendizagens nos campos temáticos propostos pelas disciplinas (MORENO et.al., 2007, p. 456). 
Figura 4a. Mapa conceitual do grupo especialista inflamável - tópico líquidos inflamáveis.

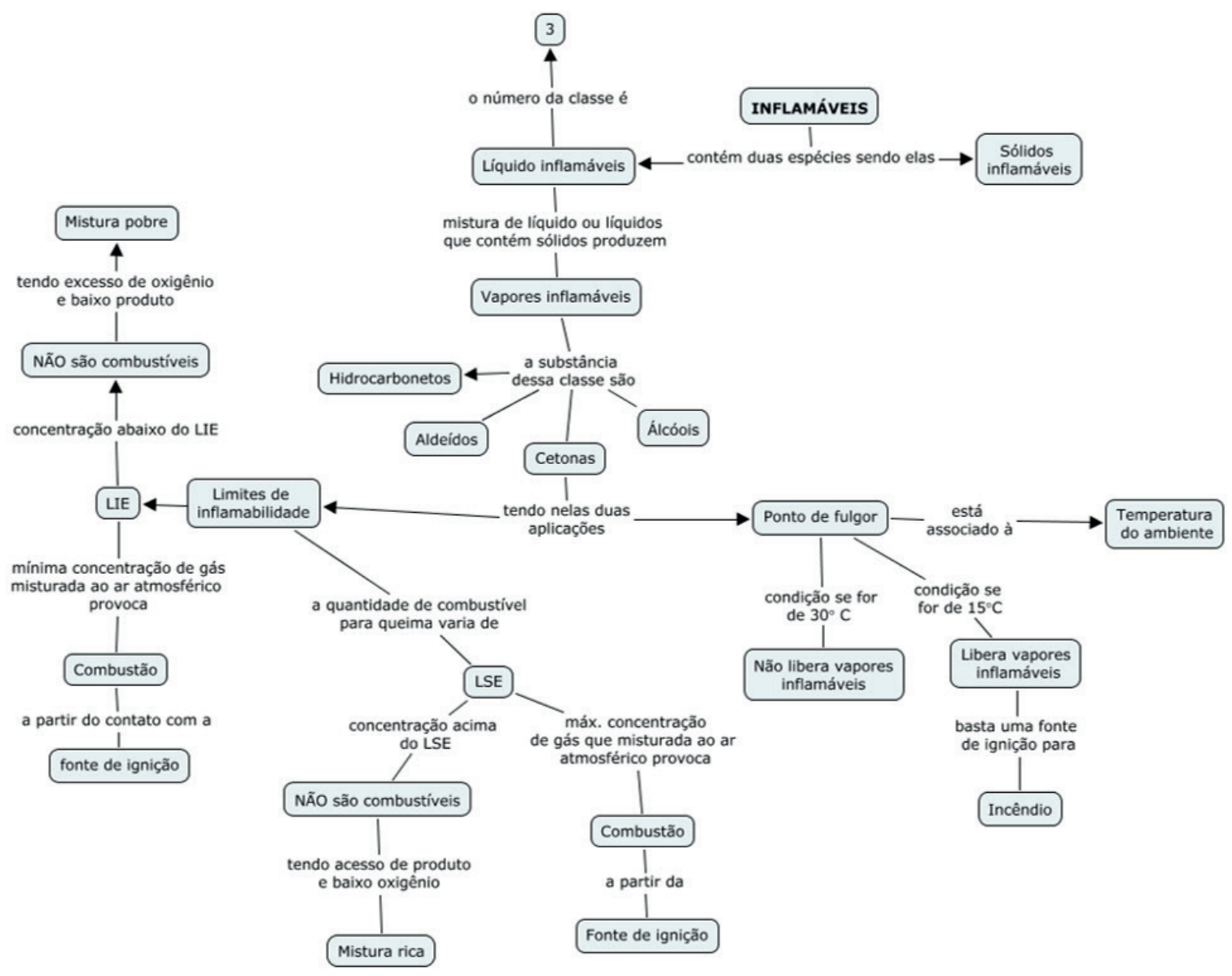

Fonte: elaborado pelas autoras. 
Figura 4b. Mapa conceitual do grupo especialista inflamável - tópico sólidos inflamáveis.

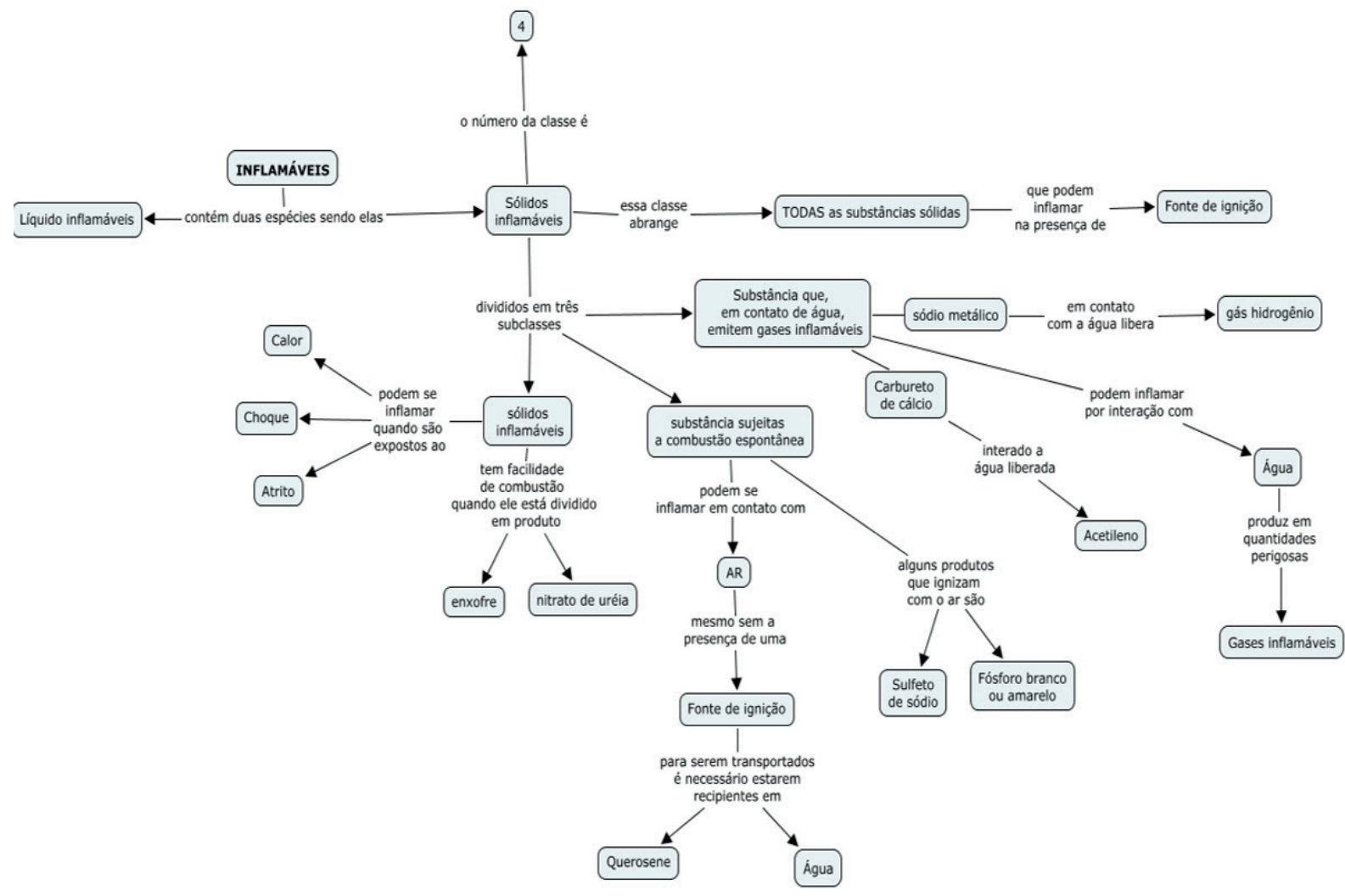

Fonte: elaborado pelas autoras.

Critério 1- Conceitos: São organizados cinquenta conceitos em caixas, de modo que o conceito mais geral (inflamável) encontre-se no topo do mapa, logo os conceitos secundários (as classes de substâncias inflamáveis e exemplos dessas classes) e posteriormente na base do mapa, estão os conceitos mais específicos (características das substâncias inflamáveis). Considera-se que há prioritariamente três níveis hierárquicos. O nível 1 que expõe as classes de substâncias inflamáveis: líquidos inflamáveis e sólidos inflamáveis. O nível 2 que cita os exemplos de substâncias inflamáveis: hidrocarbonetos, aldeídos, cetonas, alcoóis, além de carbureto de cálcio e sódio metálico em contato com água. O nível 3 detalha as características dessas substâncias: limite de inflamabilidade, ponto de fulgor e modo de transporte.

Critério 2- Inter-relações: Há uma relação clara e completa entre os conceitos. Todos os tópicos citados constavam no material de apoio o qual os alunos do grupo especialista estudaram para confeccionarem o mapa.

Critério 3- Estrutura do mapa: O mapa é estruturado de modo hierárquico e não há presença de relações cruzadas. Apesar de diversificadas informações, o mapa é esteticamente claro e compreensível e abrange questões detalhadas sobre as substâncias inflamáveis.

Nível do mapa: Satisfatório. Percebe-se que grupo conseguiu interligar bem os conceitos.

O terceiro encontro, marcado pelo retorno dos alunos aos grupos de base, foi caracterizado por uma breve exposição oral do mapa conceitual especialista. Nesse momento, houve a troca de conhecimentos em uma perspectiva integradora, ou seja, cada aluno explicava seu tópico, a fim de que todos compreendessem os processos envolvidos na estação de tratamento de água. Ao final, os grupos de base discutiram possíveis recursos que poderiam compor a cartilha que seria apresentada no último encontro. 
No último encontro foi realizada a apresentação das cinco cartilhas lúdicas confeccionadas pelos cinco grupos de base. As cartilhas digitais foram apresentadas no período de 20 minutos por cada grupo de base. Os alunos esclareceram o porquê escolheram um recurso específico para tratar o assunto de periculosidade das substâncias perigosas e como confeccionaram as atividades. Os discentes realizaram algumas atividades da cartilha com a turma durante a apresentação. As propostas expostas foram: palavras cruzadas, caça palavras, dominox, curiosidades, mito e verdade e jogo da memória. Um grupo de base também simulou uma conversa entre um técnico em segurança do trabalho e um trabalhador sobre os riscos de certas substâncias químicas. As apresentações de todos os grupos foram feitas com auxílio de slides estruturados no Power Point.

Observou-se que grande parte dos alunos demonstrou um domínio no assunto explicitado, pois conseguiram explicar o conteúdo com segurança e com detalhes, além de demonstrarem empolgação na realização dos passatempos em sala.

\section{CONSIDERAÇÕES FINAIS}

A análise dos dados evidencia que a proposta didática é viável. Com relação ao método Estudo de Caso destaca-se que sua aplicação no início da aula atuou como um recurso estimulador aos alunos. Eles assumiram uma responsabilidade de estudar e compreender sobre o assunto de periculosidade das substâncias de modo cooperativo e atuar como agente ativo em aula.

O uso da dinâmica de sala baseada na aprendizagem cooperativa Jigsaw proporcionou um ambiente interativo, no qual os alunos partilhavam os conhecimentos, aceitavam opiniões postas ao grupo, alguns questionavam e outros solucionavam as dúvidas que surgiam, ou seja, houve uma troca de conhecimentos. Cada integrante assumiu uma responsabilidade individual de modo ativo e participativo, com a qual todos contribuíram para o andamento das atividades.

Identificou-se que o mapa conceitual é um recurso de aprendizagem que pode ser utilizado como instrumento de avaliação de aprendizagem, pois seu uso possibilita ao aluno externalizar suas interpretações ao criar seu mapa conceitual. Nesse momento, há uma oportunidade dos alunos comunicarem entre si e trocarem ideias durante suas explicações sobre o mapa. A respeito da apresentação dos grupos de base identificou-se que grande parte dos alunos demonstrou um domínio no assunto explicitado, pois conseguiram explicar o conteúdo com segurança e com detalhes. A criatividade também foi identificada nos trabalhos.

\section{REFERÊNCIAS}

ARAÚJO, U. F.; FRUCHTER, R.; GARBIN, M. C.; PASCOALINO, L. N.; ARAÚJO, V. A. A. The reorganization of time, space, and relationships in school with the use of active learning methodologies and collaborative tools. ETD - Educação Temática Digital. Campinas: Unicamp, v. 16, n. 1, p. 84-99, 2014. Disponível em: http://www. brapci.inf.br/index.php/article/view/0000018044/64ca044a4a1ed54cfdd8fbb5bdaf1e2a/. Acesso em: dez. 2017.

BERBEL, Neusi Aparecida Navas. As metodologias ativas e a promoção da autonomia dos estudantes. Semina: Ciências Sociais e Humanas, Londrina, v. 32, n. 1, p. 25-40, jan./jun. 2011.

COCHITO, M. I. G. S. Cooperação e aprendizagem: educação intercultural. Lisboa: ACIME, 2004. Disponível em: <http://cidadaniaemportugal.pt/wp-content/uploads/recursos/cooperacao-e-aprendizagem.pdf>. Acesso em: dez. 2017. 
FATARELI, E. F.; FERREIRA, L. N. A.; FERREIRA, J. Q.; QUEIROZ, S. L. Método Cooperativo de Aprendizagem Jigsaw no Ensino de Cinética Química. Química Nova na Escola, v. 32, n. 3, p. 161-168, 2010. Disponível em: http://webeduc.mec.gov.br/portaldoprofessor/quimica/sbq/QNEsc32_3/05-RSA-7309_novo. pdf. Acesso em: dez. 2017.

HERREID, C. F. Case studies in science - A novel method of science education. Journal of College Science Teaching, v. 23, n.4, p. 221-229, 1994. Disponível em: http://sciencecases.lib.buffalo.edu/cs/pdfs/Novel_ Method.pdf. Acesso em: dez, 2017.

MENGDUO, Q.; XIAOLING, J. Jigsaw Strategy as a Cooperative Learning Technique: Focusing on the Language Learners. Chinese Journal of Applied Linguistics (Bimonthly), v. 33, n. 4. Retrieved from, 2010. Disponível em: http://www.celea.org.cn/teic/92/10120608.pdf. Acesso em: dez. 2017.

MORENO, L. R.; SONGSONO, M. C.; BATISTA, S. H. S.; BATISTA, N. A. Mapa conceitual: ensaiando critérios de análise. Ciência \& Educação, v. 13, n. 3, p. 453-46, 2007. Disponível em: http://www.scielo.br/scielo. php?script=sci_arttext\&pid=S1516-73132007000300012\&lng=en\&nrm=iso\&tlng=pt. Acesso em: dez, 2017.

SÁ, L. P.; QUEIROZ, S. L. Estudo de casos no Ensino de Química. Campinas: Editora Átomo, 2009 